\title{
Narrative Identity in the Social World: The Press for Stability
}

\author{
Kate C. McLean ${ }^{1}$ \\ Moin Syed ${ }^{2}$ \\ Kristen Haraldsson ${ }^{1}$ \\ Lexi Lowe ${ }^{1}$ \\ ${ }^{1}$ Western Washington University \\ ${ }^{2}$ University of Minnesota
}

McLean, K. C., Syed, M., Haraldsson, K., \& Lowe, L. (in press). Narrative identity in the social world. In P. Corr \& G. Matthews (Eds.), Handbook of Personality Psychology. Cambridge, UK: Cambridge University Press.

Author Note. We thank Anna Ciao, Brianna Delker, Annie Riggs, and Joy Wiggins for comments on an earlier draft of this manuscript. 


\section{Narrative Identity in the Social World: The Press for Stability}

Narrative as a component of personality has a long history in the field, but it is only within the last two decades that it has been fully accepted into contemporary approaches to personality (e.g., McAdams \& Pals, 2006). One part of the flourishing of the field of narrative psychology has been the attention paid to the social and cultural contexts of narrative production. Yet this work has been somewhat outside the reach of personality psychology, occurring more often within the fields of developmental, cognitive, and social psychology (e.g., Fivush, Haden, \& Reese, 2006). One of the reasons for this separation is the attention to how social and cultural contexts change narration, and a focus on malleability in psychological phenomena has not traditionally been under the purview of personality psychology. We aim to merge these areas of study - personality and social and cultural contexts of narration - by focusing on the role that those contexts play in the stability of narrative as a component of personality.

We accomplish this aim by unpacking the theoretical and empirical work on the social nature of narrative from its origins in the focus on dyadic and conversational processes of sharing stories with others, to more recent work that seeks to capture the social nature of narrative in its cultural context with an examination of master narratives. We couple our review of the empirical work with a discussion of methodological approaches, concluding with new questions for the future. But, to begin, we review the theoretical framework we employ: McAdams and Pals' (2006) approach to personality, in which personality is represented by five principles - evolution, traits, characteristic adaptations, narrative, and culture.

\section{A Comprehensive Framework for Conceptualizing Personality}


The study of narrative within the realm of personality has been articulated within 'The New Big Five,' a framework developed by McAdams and Pals (2006). The framework includes five principles for conceptualizing personality. There are two principles that are relevant to how personality is expressed in individual lives, which bookend what have been termed 'levels' of personality. At one end, is the first principle that captures individual variability expressed as part of our evolutionary design. The fifth principle concerns the ways in which cultural contexts impact how personality is expressed. Between these two principles of evolution and culture, lie three levels of personality that can be conceptualized as a continuum moving from personality as more rooted in biology and similarities across people, towards personality conceptualized as greater contextual variability between people.

The first level is personality traits, most often defined as The Big Five (Costa \& McCrae, 1994), or more recently as the hierarchical big five, in which the big five domains comprise lower order aspects and facets and are situated within two higher-order meta-traits (DeYoung, 2015). At this level we see variation between people rooted along the five continua of these dispositions (openness, conscientiousness, extraversion, agreeableness, neuroticism), which are viewed as relatively rooted in early temperament, biology, and genetics (McCrae \& Costa, 2008). Indeed, contextual variation at the level of traits is 'smoothed over,' with an emphasis on generalized, or aggregated, patterns across situations.

The second level is termed characteristic adaptations, and focuses on variability that is more contextualized within particular developmental contexts. Here, the focus is on personal goals, generalized schemas (e.g., attachment), and motives (e.g., power and intimacy). McAdams and Pals (2006) suggested that this is the level through which traits are enacted in 
daily life as individuals pursue a particular agenda (see also McAdams, 2015). Thus, variation at this level becomes more contextual, as one moves through life stages, or develops new goals or agendas, or different schemas for understanding the world.

The third level concerns narrative as represented by the life story, an internalized and evolving story that serves to integrate and give purpose to the individual. As people recall and reconstruct the past events of their lives, they construct the most unique part of their personality - the level that defines their identity. Life stories contain high points, low points, themes, values, and goals, with the aim of capturing the past, present, and future self. Across the many narrative episodes collected in the life story, researchers aggregate the patterns across episodes to capture the general patterns of narration (e.g., McAdams, Anyidoho, Brown, Huang, Kaplan, \& Machado, 2004), or assess specific narrative episodes as a component of narrative processing (e.g., McLean \& Breen, 2009; Syed \& Azmitia, 2008) ${ }^{1}$. It is the variation in these narrative patterns that captures personality at this level.

Level three is the most contextualized, or 'protean,' aspect of personality, and is thus, more socially and culturally informed than traits, which are viewed as an amalgam of behavior averaged across situations. In reviewing the field, we build on this framework, but focus on how the malleability or contextual variability that has been central to thinking on narration has obscured how these contexts can also promote stability in narration. This is particularly important, as stability is part of what defines a psychological phenomenon a part of personality - patterns of individual variability that show some consistency across time and context.

\footnotetext{
${ }^{1}$ See Syed (2017) for a discussion of narrating the life story versus specific episodes within a personality framework.
} 


\section{Theoretical Foundations}

The field of narrative identity derives from a long history within personality psychology that focuses on the role of narration as an individual difference that targets both implicit aspects of personality (e.g., TAT, Murray, 1938), as well as explicit reports of one's life (McAdams, 1985). But with the rise of trait psychology, such conceptions of personality were falling through the cracks. As described above, narrative identity was instantiated as an empirical area of study through the work of Dan McAdams (e.g., 1985; 1993), who argued for narrative as a 'level' of personality, paying particular attention to the need for a broader conceptualization of personality beyond traits. One of the components of McAdams' original argument was the importance of attending to cultural contexts in understanding personality, something that was often lost in the original surge of attention to personality traits. Indeed, McAdams and Pals (2006) argued, "The complex interplay between culture and human individuality may be most evident at the level of narrative identity" (pp. 211). However, much of the work in this area has emphasized how contexts can move narrative around, a point we question here.

Does Contexualized Always Mean Change?

In short, viewing narrative as the most 'protean' level of personality, may have overprivileged attention to change. For example, much of the research on audience effects on narration and cultural differences in narrative production highlights how these contexts can change the story one is telling. Such an emphasis may have muted the powerful forces that cultural and social contexts can play in maintaining stability in one's stories. There are several ways in which this muting may have occurred. 
The first is the notion that individuals' motives, goals, and decisions in particular moments of social life drive the kind of story they tell, and the way they tell it (e.g., Pasupathi, 2001). Attention to these components of storytelling is certainly critical for understanding what is happening in a storytelling situation, but they also privilege the individual's agency in shaping that context (cf., McLean, 2015; McLean \& Syed, 2015). The notion that we are the authors of our own stories often leads to an emphasis on the autonomy individuals have in how they decide to narrate their lives (see Waterman, 2015). There is choice, and thus, there is room for change as we can simply decide to tell the story in one way or another - we can change the story. McAdams and Pals (2006) emphasized the agency individuals have in this choosing, noting that "... individuals select and appropriate in the making of narrative identity" (pp. 212), likening this process to making a 'choice' on the menu of cultural options for storytelling.

Yet social and cultural contexts provide a strong constraint for how to story ourselves (McLean, 2015; McLean \& Syed, 2015) - the menu is fixed after all, at least to some extent. And this constraint may privilege stability in the kinds of stories that are told, regardless of our goals and motives. Second, even as we may choose to tell stories in a certain way, when those stories are validated by others, they begin to stick (see Pasupathi, 2001). That is, the social force of storytelling can work to instantiate particular stories, especially those that fit the cultural mold and are thus agreeable to the listener (Syed, Pasupathi, \& McLean, in press). In this way, listeners are not only agents of change, but also forces for stability. ${ }^{2}$

\footnotetext{
${ }^{2}$ We note that we do not expect that McAdams and Pals (2006), or other theorists, would disagree with this notion of constraint; it is more an issue of emphasis. The emphasis has been on agency and change (see also McLean \& Syed, 2015), to the neglect of the role of social and cultural context as forces for stability.
} 
Theoretical Beginnings: Personal Memory Telling

The seeds of these ideas about social narration as a force for stability come from Thorne's (2000) work connecting personal memory telling to processes of personality. The premise of Thorne's work - that the social context of narration was important - was distinct from the great majority of theorizing and empirical work in personality at the time, which was reticent to (or even antagonistic towards) taking on social contexts, as a part of personality. Personality was internalized, individual, biological, and stable (Block, 1981; Costa \& McCrae, $1980 ; 1994)$. Part of this tension was the history between the worlds of personality and social psychology in which the social context was used as a threat to the validity of personality (Block, 1981; Mischel \& Peake, 1982). And part of this was a history of measurement and theoretical tradition that put the lens on the person (e.g., self-reports, interviews, q-sorts), as opposed to the social context of personality (cf., Thorne, 1987).

The crux of Thorne's argument was not simply that stories are used in social settings such as for entertainment, which they are - but rather that narratives "drive personality development in concrete moments of social life" (p. 45). Thorne argued that sharing personal stories with others is not only an example of both 'reciprocal interactionism' (Endler, 1981) how persons and situations influence each other - it is also an example of cultural dynamism. That is, through the proximal context of sharing stories we have access to the larger cultural constraints and affordances that feed into a story and a self.

Monisha Pasupathi provided further evidence for the importance of social contexts in narration but her argument was forged more from cognitive and social psychology traditions. Like Thorne, Pasupathi argued that development occurs in social contexts, and that many of 
those contexts are rife with the disclosure of personal narratives. Pasupathi's basic premise was that when we tell stories to others, their responses shape how we later remember and recall those stories (see also McLean, Pasupathi, \& Pals, 2007). Her work emphasized the particularities of these 'telling' contexts, such as the goals or motives a person brings to the sharing of a story, as well as specific variations in the responses of listeners (e.g., disagreeable or attentive). Pasupathi's work was not grounded in personality, and she emphasized more heavily the mutability of narrative in social contexts - how these moments of social narration can change the story told (and remembered). However, the theoretical framework can be used to understand stability in narration as well.

\section{Theoretical Development: Master Narratives}

The original work done by Thorne and Pasupathi to forge a theoretical framework for thinking about the sharing of stories, fed into a more recent framework for understanding the cultural dynamics of narrative identity development that centers on master narratives. The idea that the responses of audiences can impact the stories we tell and remember, suggests that there is a 'correct' way to tell a story, or a story that pleases or displeases a listener. These audience desires are shaped by master narratives - culturally shared templates for stories that guide thoughts, feelings, and actions (Hammack, 2008; McAdams, 2006; McLean \& Syed, 2015; Thorne \& McLean, 2003). These stories are not about individual personal experiences, but rather serve as broad cultural templates for how to tell particular types of stories. And these templates can enforce a certain kind of story, with sanctions for those whose stories do not align with the template. 
In describing their master narrative framework, McLean and Syed (2015) outlined five core principles that explain the strength of master narratives, which may also help to explain how they facilitate stability in stories. In brief, master narratives provide useful information for how one ought to be and how one's stories ought to unfold (utility). They permeate many aspects of society, in family life, institutions, and the media (ubiquity). They are cast as natural, so they are rarely even noticed or named by those who align with them (invisibility). It is expected that most members of a society will adhere to them, and there are often real risks to deviating and endorsing an alternative narrative (compulsory). And, perhaps most important for the current argument, they gain their power from being resistant to change in order to maintain cultural dynamics (rigidity).

These five principles work together to give master narratives their social power in individual lives. And they may also work together to push for stability in narrative, providing a socio-cultural explanation for why our stories are stable. The constraints of master narratives can provide great stability in the ways that identities are defined, both in the possibilities for self-definition that exist in a given context (i.e., the cultural menu), and in the ways that sanctions are imposed for those who do not align.

In sum, the simple and ubiquitous act of sharing a personal story with another person is a moment in which personality processes are enacted in the decision to tell a story, the ways in which stories are shared, and the responses from an audience. What is shareable, how it is shared, and responses to the story are shaped not only by aspects of the immediate situation, such as the listener, but also by cultural norms and values. Further, if these cultural expectations for storytelling are violated, consequences may follow. Those processes can 
create change in personality, such as the subtle, or not so subtle, prompts from others to revise one's story, to re-interpret it. But these processes can also create stability in personality: shaping a story to meet others' expectations, coupled with validation from those others, works to calcify one's story. Thorne and Pasupathi led the charge to elaborate and contextualize this level of personality with their attention to the social nature of narrative, laying the theoretical ground work for the study of the "personal" story as a joint production. And the empirical work soon followed.

\section{Empirical Foundations of the Social Nature of Narrative}

In reviewing the empirical work, we draw from Thorne and Pasupathi's original studies, and discuss the distinct methods that each used to target the social processes of narration. We distinguish those studies that have taken a more subjective approach - assessing the recollection of shared stories, versus a more objective approach - the observation of storytelling, to highlight methodological variation. We follow with a review of the recent work on master narratives.

The Subjective Assessment of Tales Told: Methods and Findings

Building directly from her theoretical proposals, Thorne and colleagues (Thorne, McLean, \& Lawrence, 2004), began to investigate the landscape of memory telling. These initial studies were self-report assessments of having told memories to other people, a common measurement technique in personality psychology (Adler, Dunlop, Fivush, Lilgendahl, LodiSmith, McAdams, McLean, Pasupathi, \& Syed, 2017). Participants are asked to write down an important memory in narrative form, and are then asked if they have told it. If so, they are asked to describe that 'telling narrative' (McLean, 2005; Thorne et al., 2004). These layers of 
narratives can be used to understand the person's own take on their experiences, as well as some of the social ecologies in which those experiences are shared. These subjective accounts are objectively coded for various attributes (Syed \& Nelson, 2015), such as the degree of personal meaning included in the narrative, how positive or negative the story is, and how positive or negative the response of the listener was.

Initial descriptive work revealed that people tell their stories - a lot. Almost $90 \%$ of selfdefining memory narratives, elicited from emerging adult college students, had been told at least once to someone else in the past. This high percentage of shared memories has held remarkably constant across various types of narrative prompts and samples (e.g., McLean, 2005; Pasupathi, McLean, \& Weeks, 2008; Rimé, Mesquita, Philippot, \& Boca, 1991). Even those stories that we don't remember over the long term, such as the most interesting thing that happened to you today, are more likely to be told soon after their occurrence than not (Pasupathi et al., 2008). This baseline descriptive evidence tells us, at minimum, that not studying that social context (e.g., what happens when these stories are shared) means that we lose a large part of our understanding of the phenomenon of personal narrative as a part of personality.

Building on the description of the phenomena, McLean (2005) investigated the reasons for telling memories (see also Bluck \& Alea, 2009). As Pasupathi (2001) argued, the reasons one has for telling a story can impact the way the story is told as well as the response of a listener. If I tell a traumatic experience because I need comfort, the story will look different than if I tell it as a testament to my personal strength. Descriptively, McLean (2005) found that telling selfdefining memories for self-related reasons (e.g., self-explanation, meaning-seeking, personal 
validation) was quite common, and was more closely related to narratives that had more elaborated meaning-making. In other words, when people tell stories with reasons related to communicating who they are, those stories have more elaborated explanations of who they are. If I tell that trauma with the interpretation of my personal strength and resilience - the story tells you a lot about who I am via my explicit statements about who I am. If I tell it to entertain you, the meaning it has to my identity will be less explicit (McLean \& Thorne, 2006).

The savvy (or disagreeable) reader might be muttering that there are certainly remembered stories that are unshared; perhaps you can even think of a few of your own. And, indeed, there are. In particular, the telling of transgressions - at least in American contexts - is less common (Pasupathi et al., 2008). In a cultural context in which positive self-evaluations are king, why would one tell stories about one's misdeeds? Yet this does not mean that transgressions are not shaping and shaped by the social world. One major reason people are less likely to tell such stories is fear of social shaming. Put differently, these stories are not culturally acceptable; these selves are not culturally acceptable. So they are hidden away, and shape a cultural world with limited access to discussion of transgressions.

But not so in all groups. For example, in observational studies of conversations between parents and children, we see that Chinese American parents talk about their children's wrongdoings as a mechanism of value and behavioral socialization more so than White American parents (e.g., Wang \& Leichtman, 2000). Similarly, in samples of White Americans, working class families discuss transgressions more than middle class families (Miller, Sandel, Liang, \& Fung, 2001). In these families where transgressions are more available for discussion, they appear to be a useful tool for socializing behavior and protecting children from potential 
threats. What we can take from this - and it is an important lesson - is that the social and cultural context influences both the affordances for and the barriers to sharing stories, and when those stories are shared (or not shared) they maintain the cultural context that includes those affordances and barriers.

These initial studies were biased by the subjective nature of the recollection. That subjectivity is still important, perhaps particularly to the study of personality because such recollections still tell us a good deal about the person. But what happens in vivo? The Objective Assessment of Tales Told: Methods and Findings

While Thorne and colleagues were examining recollections of experiences with telling personally important stories, Pasupathi was driven by her training in experimental methods to focus on the actual conversations in which narratives were shared. Across multiple studies, evidence accumulated showing that the manner in which audiences respond to a shared story predicts whether and how that story is retained, as well as its self-relevance over time (Pasupathi \& Hoyt, 2009; Pasupathi \& Rich, 2005). For example, you come to the lab and share something (relatively trivial) to an audience who is distracted or attentive (via experimental manipulation). With an attentive, supportive audience you later remember the story better, and think it is more self-relevant. You forget details, or dismiss the importance of stories told to an audience who is distracted. This kind of work shows the real power of close others to shape our stories - not only how they are told, but if we remember them at all!

This research is consistent with that conducted in a parallel field also focused on examining conversations about past events. But these researchers were driven to understand childhood amnesia, and were focused on the importance of parent-child conversations about 
past events as drivers of developing an autobiographical self, or a self that extends through time (see Fivush et al., 2006 for a review). These researchers took a socio-cultural approach to their studies, viewing these conversations as moments of scaffolding, in which parents supported their children's growing ability to narrate the personal past. The manners in which parents engaged in this support, somewhat analogous to variations in distraction and attentiveness in Pasupathi's studies, predicted the behavior of the children in the conversation at the moment, in subsequent conversations over time, as well as the child's recollection of the personal past in non-conversational contexts (see Reese, Yan, Jack, \& Hayne, 2010 for an example). Though not necessarily focused on stable individual differences, this work provided methodological opportunities.

Indeed, in conversational studies, the methods shift. First, the personal story must be captured, which can be done in ways similar to those self-report methods (e.g., is the shared story positive or negative, meaning-laden, or sparse). Second, the manner of the response must also be captured. For example, researchers can code each utterance of the audience responses for whether they validate or support the speaker, or whether they disagree or reframe what the speaker has shared (e.g., Bird \& Reese, 2006; Haden, Haine, \& Fivush, 1997; McLean \& Mansfield, 2011). Further, it is not always the case that participants are sharing their most important, or identity-defining stories. Indeed, some studies have used laboratoryinduced events to share or more everyday experiences (Pasupathi \& Rich, 2005). Others have used emotional events (e.g., sad, happy; McLean \& Mansfield, 2011), but little research has focused on self-defining, turning point, or other 'life story' type memories. This makes good sense because participants may not always be willing to share such memories; these are the 
types of memories that may be reserved for more intimate conversations, or very particular audiences.

These techniques for capturing conversations, as currently used, give us insight into conversation processes related to narration, but how much of those processes translate to the life story, writ large, is still unclear. McLean and Pasupathi (2012) suggested that, over time, these micro contexts of storytelling accumulate into the larger stories embedded within the life story. It is as if everyday storytelling serves as practice for the kinds of stories that define us in the life story. Once our life story becomes more solidified, perhaps the everyday storytelling is a way to maintain that solidity of who we are. But this kind of claim demands methods to capture these micro processes over time, and as they connect to the larger story that is developing (see Kunnen \& Metz, 2015 for related methods on another topic).

Based on these initial findings, it is clear that narrative construction is inherently social. We follow the storyline of empirical work to scale up from these dyadic conversations to an examination of the broader social context, by discussing the findings related to how the cultural nature of master narratives can push for stability in narrative.

Master Narratives and the Stability of Narrative

As we have discussed, the notion of stability of psychological phenomena is a cornerstone of any approach to the study of personality. In fact, some of the first empirical endeavors in the field of narrative identity were conducted to show that there was some stability in narrative patterns over time (McAdams, Bauer, Sakeda, Anyidoho, Machado, Magrino-Failla, White, \& Pals, 2006; Thorne, Cutting, \& Skaw, 1998). These initial studies were critical to making the argument that narrative was actually a part of personality, but they were 
quite distinct from the theoretical traditions of Thorne and Pasupathi because the social context was not considered in these examinations of narrative stability. However, merging these social constructivist theories and personality theories, we can see that such contexts may help to explain some of the stability of narrative.

At the most basic level, several theorists have made the argument that sharing personal stories helps us to develop a story that is socially acceptable, and once we get that acceptable story down, that is the story that we will stick with (McLean, Pasupathi, \& Pals, 2007; Pasupathi, 2001). Aspects of self, such as personality, influence when and how stories are constructed and shared, but the sharing feeds back into those selves to solidify them, akin to active and evocative forces (McLean et al., 2007). From this perspective, the micro processes involved in storytelling conversations can serve to stabilize narrative.

Beyond the immediacy of a listener response, there is a strong bi-directional relation between individual and culture in this kind of model, and the dynamics are strongly tuned to maintaining master narratives (McLean \& Syed, 2015), increasing solidity in cultural and personal stories. Thus, if we see stability in the ways that some people tell the ending of their stories - for example, with resolution - this may be because positive resolution is a culturally desirable story characteristic. (at the distal level). So people are more likely to end their stories positively because of the social feedback they receive that this is the correct way to construct a narrative (at the proximal level). As they continue to tell stories this way, it reinforces the interpersonal and cultural value placed on resolution.

This premise concerning the bi-directional nature of personal and master narratives is well-exemplified in Phil Hammack's (2011) culturally sensitive analysis of identity development 
in Israeli and Palestinian adolescents. In extensive life story interviews, he found that the historical story of these two groups, the master narrative for each, was embedded within their personal narratives (e.g., the holocaust and subsequent return to Israel; the disruption and division of one's homeland). This is a theme of master narrative work: one can see master narratives in personal narratives, if reading for them (Galliher, McLean, \& Syed, 2017).

Further, the fact that these historical, master narratives appeared in personal narratives is one way that master narratives maintain their power - they are retold each time an individual tells his or her own story. Even more, Hammack found that the ways in which these adolescents negotiated their own identity stories with these larger cultural stories shaped the cultural and historical context by maintaining divisions between groups. It turned out that, for these kids, defining oneself as Israeli necessitated an anti-Palestinian identity, and vice-versa. This act of personal storytelling upholds the current structures of a cultural context, and the stories that infuse it.

This is one of the more powerful studies to reveal the ways in which culture impacts the individual, and how the individual impacts culture. In this way culture is not the independent variable, which is static and separated from the individual. Instead culture and the person are engaged in a bi-directional interaction. And when stories are told in ways consistent with that cultural framework, the framework, or master narrative is maintained - one explanation for the stability of stories.

At a more meta-level, some cultures may also press for stability and predictability themselves. In American culture, there is an emphasis on continuity across contexts - we want to be able to predict how ourselves and others will act. So the emphasis on stability may come 
from aligning with cultural expectations, which are relatively static, and also with the expectation for predictability and stability itself.

We have argued that these master narratives press for stability in stories, and this may be one reason that we see stability in narrative patterns over time. But we have yet to fully link individual differences to these social and cultural processes. We close the chapter with a discussion of the linkage between individual differences in personality and master narratives raising ideas that are largely untested, as of yet.

\section{Master Narrative Negotiation and Personality: Ideas for the Future}

Master narratives have yet to be clearly incorporated into a model of personality. They have been used to study identity and culture, but not necessarily individual differences. We have argued that the concept of master narrative helps us to understand stability in narrative. But we want to push the master narrative model a bit more into the territory of personality by playing with some ideas about the process of negotiation with master narratives.

In thinking about variation in engagement with master narratives, there is a critical piece of the framework to which we have only alluded so far, which are the societal power dynamics that must lie at the center of the analysis of master narratives (McLean \& Syed, 2015; Syed, 2016). Master narratives are not value-neutral. In governing what is good, just, and acceptable in society, master narratives reinforce the norms established by those who hold power. Indeed, those who are in more marginalized positions by virtue of ethnicity, gender, or sexuality, report being more likely to deviate from the master narrative (McLean, Lilgendahl, Fordham, Alpert, Marsden, Szymanowski, \& McAdams, 2017). Such individuals are also more like to elaborate alternative narratives, those that are counter to the master narrative, 
providing a different framework with which to define the self (McLean et al., 2017; see also Juan, Syed, \& Azmitia, 2016; Gyberg, Frisén, Syed, Wängqvist, \& Svensson, 2018; McLean, Shucard, \& Syed, 2017; Way \& Rogers, 2015). Alternative narratives are stories that are in resistance to, or divergent from, the normative expectations. They provide a different cultural framework for those who are marginalized from the mainstream or dominant powers.

Whether one deviates from the master narrative is not necessarily a question of personality, but how one manages or responds to the deviation may be a place ripe for investigation of individual differences. For example, one may deviate from the master narrative through no choice of one's own (e.g., being a sexual minority). But aligning oneself with an alternative narrative is an agentic process (Toolis \& Hammack, 2015), which takes more intensive, thoughtful identity work or reflection. For example, we have found that those who not only deviate, but also elaborate an alternative narrative, score higher on identity exploration processes (McLean, Lilgendahl et al., 2017; see also McLean, Shucard et al., 2017). Though the press to align with an alternative narrative may be high - at minimum to find a place to belong - it does take personal effort, and some people may be more inclined towards this reflective task.

In thinking about how components of personality might illuminate these processes, at level two, constructs like ego development may relate to engaging in the work of understanding the intricacies of the master and alternative narrative negotiation process. Those higher on ego development have greater complexity of thought (Loevinger, 1976) - seeing greater perspective, nuance in emotions, and are less rigid in their thinking - the kinds of skills that might allow one to find a home in an alternative narrative. At level 1, agreeableness may 
facilitate obtaining others' understanding of personal experiences of deviation, and extraversion may facilitate finding the group with which one resonates (we do know that extraverts tell their stories more, and take more pleasure in sharing their stories with others; McLean \& Pasupathi, 2006). In terms of those who align with the master narrative, of course demographics play a role, but perhaps also low openness to experience. Those with more inflexible outlooks on life may be less likely to engage with alternate possibilities for defining the self.

It is also the case that finding and connecting to an alternative narrative may take some risk. For example, when put in conversational contexts, these alternative narratives become less visible as people are reticent to 'out' themselves as deviating from the norm, instead using master narratives to discuss personal experience, even when personal experience does not match those master narratives (McLean, Shucard et al., 2017). It appears that individuals would rather find common ground, and not feel marginalized, than disclose a story that runs counter to expectations. Perhaps other components of personality may be important in facilitating risky exploration, such as attachment security, or generalized self-esteem, which may allow a comfort with risking the self.

Beyond thinking about who is likely to engage in processes of negotiating with alternative and master narratives, we can also think about the degree to which one internalizes master and alternative narratives. That is, it may not be a binary - you belong to one or the other - but a matter of gradation. Some people go whole hog with the master or alternative narrative, living a life or telling a story in complete alignment with expectations of either narrative. Yet others may adopt a softer version, or bits and pieces. This softer version may be 
represented by not adopting all components of the master or alternative narrative, or by adopting these narratives in less centrally-defining ways (for other similar process see Yoo, Burrola, \& Steger, 2010 on internalization of the model minority myth; David \& Okazaki, 2006 on colonial mentality; Benet-Martínez \& Haritatos, 2005 on bicultural identity). For example, there is a biographical master narrative in the U.S. that includes events such as finishing school, finding a job, getting married, and having a child. A person may adopt some of these - an education, job, marriage, but no child. Or a child but not a marriage. This would be a piecemeal version. One may also be married, but not find that to be centrally-defining, which would be another way to soften conformity, perhaps especially for a woman.

At the beginning of this section we raised a central component of the master narrative framework, which is the importance of power dynamics. Indeed, this distinction in how much a narrative is centrally defining may be particularly important for those who do not align with the master narrative. For those who align with the master narrative, but don't view it as central, this is not problematic because one is still fitting in with cultural expectations, and in a position of greater power. In contrast, for those who do not adopt the alternative narrative, they might be left more isolated, more at risk, less empowered. In a recent paper (McLean, Lilgendahl, et al., 2017), we included a narrative from a young gay man who reported not aligning with the alternative narrative for gay individuals in the US - as he discussed it:

I've also diverged from what's considered normal and expected of a young gay male. I'm not at all feminine like many of the caricatures on TV series, etc., and don't fulfill the "gay best friend" role that a number of straight women have asked me to fulfill. 
The outcome of not adopting the alterative narrative, for this reporter, is isolation: “...makes me feel as if I'm floating in a void, fulfilling nobody's expectations but my own." Thus, personality may help us to understand these dynamics of negotiation, but maintaining a lens on the power differentials inherent to these negotiation processes is critical. Researchers must synthesize a personality and socio-cultural lens in understanding these phenomena.

\section{Conclusion}

We have used McAdams and Pals (2006) framework for understanding personality, in which cultural contexts play a role in understanding personality processes at three levels traits, characteristic adaptations, and the life story. In focusing on level three, we have made the argument that focusing on social and cultural contexts is not necessarily limited to thinking about how those contexts change, or make fluid, narrative. But, instead, we can also see how those contexts can be a force for stability in stories and storytelling. Finally, we have argued that engaging with cultural contexts by employing a master narrative framework may be a place ripe for examining individual differences. We hope these ideas serve as food for thought for those working to marry a personality and cultural approach to narration. 


\section{References}

Adler, J. M., Dunlop, W. L., Fivush, R., Lilgendahl, J. P., Lodi-Smith, J., McAdams, D. P., \& ... Syed, M. (2017). Research methods for studying narrative identity: A primer. Social Psychological and Personality Science, 8(5), 519-527.

Benet-Martinez, V., \& Haritatos, J. (2005). Bicultural Identity Integration (BII): Components, dynamics, and psychosocial correlates. Journal of Personality, 73(4), 1015-1050.

Bird, A., \& Reese, E. (2006). Emotional reminiscing and the development of an autobiographical self. Developmental Psychology, 42, 613-626.

Block, J. (1981). The Many Faces of Continuity. Contemporary Psychology, 26(10), 748-750.

Bluck, S., \& Alea, N. (2009). Thinking and talking about the past: Why remember? Applied Cognitive Psychology, 23, 1089-1104.

Costa, P. T., \& McCrae, R. R. (1980). Influence of extraversion and neuroticism on subjective well-being: Happy and unhappy people. Journal of Personality And Social Psychology, 38(4), 668-678.

Costa, P. J., \& McCrae, R. R. (1994). Set like plaster? Evidence for the stability of adult personality. In T. F. Heatherton, J. L. Weinberger, T. F. Heatherton, J. L. Weinberger (Eds.), Can personality change? (pp. 21-40). Washington, DC, US: American Psychological Association.

David, E. J. R., \& Okazaki, S. (2006). Colonial mentality: A review and recommendation for Filipino American psychology. Cultural Diversity and Ethnic Minority Psychology, 12(1), 1.

DeYoung, C. G. (2015). Cybernetic big five theory. Journal of Research in Personality, 56, 33-58. 
Endler, N. S. (1981). Persons, situations, and their interactions. In A. I. Rabin, J. Aronoff, A.M. Barclay, and R.A. Zucker (Eds.), Further explorations in personality, (pp. 114-151). New York: John Wiley \& Sons.

Fivush, R, Haden, C. A., \& Reese, E. (2006). Elaborating on elaborations: Role of maternal reminiscing style in cognitive and socioemotional development. Child Development, 77, 1568-1588.

Galliher, R., McLean, K. C., Syed, M. (2017). An Integrated Model for Studying Identity Content in Context. Developmental Psychology, , 53, 2011-2022.

Gyberg, F. Frisén, A.,Syed, Wängqvist, M., \& Svensson, Y. (2018). "Another kind of Swede": Swedish youth's ethnic identity narratives. Emerging Adulthood, 6, 17 - 31 .

Haden, C. A., Haine, R. A., \& Fivush, R. (1997). Developing narrative structure in parent-child reminiscing across the preschool years. Developmental Psychology, 33, 295-307. doi.org/10.1177/2167696817690087

Hammack, P. L. (2008). Narrative and the cultural psychology of identity. Personality and Social Psychology Review, 12, 222-247.

Hammack, P. L. (2011). Narrative and the politics of identity: The cultural psychology of Israeli and Palestinian youth. New York: Oxford University Press.

Juan, M. J. D., Syed, M., \& Azmitia, M. (2016). Intersectionality of Race/Ethnicity and Gender Among Women of Color and White Women. Identity, 16(4), 225-238.

Kunnen, E. S., \& Metz, M. (2015). Commitment and exploration: The need for a developmental approach. In K. C. McLean \& M. Syed (Eds.), The Oxford handbook of identity development (pp. 115-131). New York: Oxford University Press. 
Loevinger, J. (1976). Ego development. San Francisco: Jossey-Bass.

McAdams D. P. 1985. Power, Intimacy, and the Life Story: Personological Inquiries into Identity. New York: Guilford.

McAdams, D. P. (1993). The stories we live by: Personal myths and the making of the self. New York, NY: Guilford Press.

McAdams, D. P. (2006). The redemptive self: Stories Americans live by. New York: Oxford University Press.

McAdams, D. P. (2015). The Art and Science of Personality Development. New York: Guildford Press.

McAdams, D. P., Anyidoho, N. A., Brown, C., Huang, Y. T., Kaplan, B., \& Machado, M. A. (2004). Traits and stories: Links between dispositional and narrative features of personality. Journal of Personality, 72, 761-784.

McAdams, D. P., Bauer, J. J., Sakaeda, A. R., Anyidoho, N. A., Machado, M. A., Magrino-Failla, K., ... \& Pals, J. L. (2006). Continuity and change in the life story: A longitudinal study of autobiographical memories in emerging adulthood. Journal of Personality, 74, 13711400.

McAdams, D. P., \& Pals, J. L. (2006). A new Big Five: Fundamental principles for an integrative science of personality. American Psychologist, 61, 204-217.

McLean, K. C. (2005). Late adolescent identity development: Narrative meaning-making and memory telling. Developmental Psychology, 41, 683-691.

McLean, K. C. (2015). The Co-authored Self: Family Stories and the Construction of Personal Identity. New York: Oxford University Press. 
McLean, K. C., \& Breen, A. (2009). Gender differences in adolescent meaning-making. Developmental Psychology, 45, 702-710.

McLean, K. C., Lilgendahl, J. P., Fordham, C., Alpert, E., Marsden, E., Szymanowski, K., \& McAdams, D. P. (2017). Identity development in cultural context: The role of deviating from master narratives. Journal of Personality, 65, 1- 21.

McLean, K. C. \& Mansfield, C. (2011). The co-construction of adolescent narrative processes: Narrative processing as a function of adolescent age, gender, and maternal scaffolding. Developmental Psychology, 5, 1 -12.

McLean, K. C. \& Pasupathi, M. (2012). Looking forwards and looking backwards: Two approaches to identity development. Identity Special Issue: Reintegrating Erikson: A Theoretical and Empirical Synthesis of Eriksonian Identity Models, 12, 8 - 28.

McLean, K. C., Pasupathi, M., \& Pals. J. L. (2007). Selves creating stories creating selves: A process model of narrative self development in adolescence and adulthood. Personality and Social Psychology Review, 11, 262-278.

McLean, K. C., \& Syed, M. (2015). The field of identity development needs an identity: introduction to the handbook of identity development. In K. C. McLean, \& M. Syed (Eds.), The Oxford handbook of identity development. New York: Oxford University Press.

McLean, K. C., Shucard, H., \& Syed, M. (2017). Applying the Master Narrative Framework to Gender Identity in Emerging Adulthood: Emerging Adulthood, 5, 93-105.

McLean, K. C., \& Thorne, A. (2006). Identity Light: Entertainment Stories as a Vehicle for SelfDevelopment. In D. P. McAdams, R. Josselson, A. Lieblich, D. P. McAdams, R. Josselson, 
A. Lieblich (Eds.), Identity and story: Creating self in narrative (pp. 111-127).

Washington, DC, US: American Psychological Association. doi:10.1037/11414-005

McCrae, R. R., \& Costa, P. T. (2008). The five-factor theory of personality. In O. P. John, R. W.

Robins, \& L. A. Pervin (Eds.), Handbook of personality: Theory and research (3rd ed., pp. 159-181). New York: Guilford.

Miller, P. J., Sandel, T. L., Liang, C-H., \& Fung, H. (2001). Narrating transgressions in Longwood: The discourses, meanings, and paradoxes of an American socializing practice. Ethos, 29, 159-186.

Mischel, W., \& Peake, P. K. (1982). Analyzing the construction of consistency in personality. Nebraska symposium on motivation (pp. 233-262). Lincoln: University of Nebraska Press.

Murray, H. (1938). Explorations in personality. Oxford, England: Oxford Univ. Press.

Pasupathi, M. (2001). The social construction of the personal past and its implications for adult development. Psychological Bulletin, 127, 651-672.

Pasupathi, M., Brubaker, J., \& Mansour, E. (2007). Developing a life story: Constructing relations between self and experience in autobiographical narratives. Human Development, 50, 85-110.

Pasupathi, M., \& Hoyt, T. (2009). The development of narrative identity in late adolescence and emergent adulthood. Developmental Psychology, 45, 558-574.

Pasupathi, M., McLean, K. C., \& Weeks, T. (2008). The told and untold narrative self. Journal of Personality, 77, 89-124.

Pasupathi, M., \& Rich, B. (2005). Inattentive listening undermines self-verification in personal 
storytelling. Journal of Personality, 73, 1051-1086.

Reese, E., Yan, C., Jack, F., \& Hayne, H. (2010). Emerging identities: Narrative and self from early childhood to early adolescence. In K. C. McLean \& M. Pasupathi (Eds.), Narrative development in adolescence: Creating the storied self. Advancing responsible adolescent development (pp. 23-43). New York, NY: Springer.

Rimé, B., Mesquita, B., Philippot, P., \& Boca, S. (1991). Beyond the emotional event: Six studies on the social sharing of emotion. Cognition \& Emotion, 5, 435-465

Syed, M. (2010). Developing an integrated self: Academic and ethnic identities among ethnically-diverse college students. Developmental Psychology, 46(6), 1590-1604.

Syed, M. (2016). Power and agency in conceptualizing life stages as master narratives. Human Development, 59, 317-323.

Syed, M. (2017). Advancing the cultural study of personality and identity: Models, methods, and outcomes. Current Issues in Personality Psychology, 5(1), 65-72.

Syed, M., \& Azmitia, M. (2008). A narrative approach to ethnic identity in emerging adulthood: Bringing life to the identity status model. Developmental Psychology, 44, 1012-1027.

Syed, M., Juan, M. D., \& Juang, L. P. (2011). Might the survey be the intervention? Participating in ethnicity-related research as a consciousness-raising experience. Identity: An International Journal of Theory And Research, 11(4), 289-310.

Syed. M. \& Nelson, S.C. (2015). Guidelines for establishing reliability when coding narrative data. Emerging Adulthood, 3(6), 375-387.

Syed, M., Pasupathi, M., \& McLean, K. C. (in press). Master Narratives, Ethics, and Morality. To 
appear L. A. Jenson (Ed.), The Oxford Handbook of Moral Development. New York: Oxford.

Thorne, A. (1987). The press of personality: A study of conversations between introverts and extraverts. Journal of Personality and Social Psychology, 53(4), 718-726.

Thorne, A. (2000). Personal memory telling and personality development. Personality and Social Psychology Review, 4, 45-56.

Thorne, A., Cutting, L., \& Skaw, D. (1998). Young adults' relationship memories and the life story: Examples or essential landmarks?. Narrative Inquiry, 8(2), 237-268.

Thorne, A., \& McLean, K. C. (2003). Telling traumatic events in adolescence: A study of master narrative positioning. In R. Fivush \& C. Haden (Eds.), Connecting culture and memory: The development of an autobiographical self (pp. 169-186). Mahwah, NJ: Erlbaum.

Thorne, A., McLean, K. C., \& Lawrence, A. (2004). When remembering is not enough: Reflecting on self- defining events in late adolescence. Journal of Personality, 72, 513-542.

Toolis, E.E., \& Hammack, P.L. (2015). The lived experience of homeless youth: A narrative approach. Qualitative Psychology, 2(1), 50-68.

Wang, Q. \& Leichtman, M. D. (2000). Same beginnings, different stories: A comparison of American and Chinese children's narratives. Child Development, 71, 1329-1346

Waterman, A. S. (2015). Identity as internal processes: How the 'I' comes to define the 'me'. In K. C. McLean, M. Syed, K. C. McLean, M. Syed (Eds.), The Oxford handbook of identity development (pp. 195-209). New York, NY, US: Oxford University Press.

Way, N., \& Rogers, O. (2015). '[T]hey say Black men won't make it, but I know I'm gonna make it': Ethnic and racial identity development in the context of cultural stereotypes. In K. C. 
McLean, M. Syed, K. C. McLean, M. Syed (Eds.), The Oxford handbook of identity development (pp. 269-285). New York, NY, US: Oxford University Press.

Yoo, H. C., Burrola, K. S., \& Steger, M. F. (2010). A preliminary report on a new measure: Internalization of the Model Minority Myth Measure (IM-4) and its psychological correlates among Asian American college students. Journal of Counseling Psychology, 57(1), 114. 